\title{
Why should we perform pulmonary function test before coronary artery bypass grafting?
}

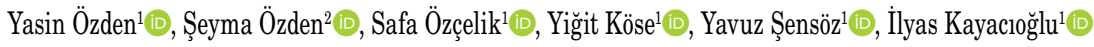 \\ ${ }^{1}$ Department of Cardiovascular Surgery, University of Health Sciences, Dr. Siyami Ersek Thoracic and Cardiovascular Surgery Training and Research Hospital, Istanbul, Turkey \\ ${ }^{2}$ Department of Chest Diseases, Immunology and Allergy Clinic, University of Health Sciences, Süreyyapaşa Chest Diseases and Thoracic Surgery Training and Research \\ Hospital, Istanbul, Turkey
}

Received: October 16, 2021 Accepted: October 30, 2021 Published online: November 12, 2021

\begin{abstract}
Objectives: In this study, we aimed to examine the relationship between preoperative pulmonary function test (PFT) parameters and postoperative length of invasive mechanical ventilation (IMV), length of intensive care unit (ICU) and hospital stay in patients who underwent coronary artery bypass grafting (CABG).

Patients and methods: Between October 2017 and July 2018, a total of 100 patients (84 males, 16 females; mean age: $61.1 \pm 10.0$ years; range, 41 to 85 years) who underwent elective CABG surgery for the first time and who did not have any additional cardiac problems, except for coronary artery disease, had an ejection fraction (EF) of $\geq 30 \%$ and underwent preoperative PFTs were retrospectively analyzed. The percent forced vital capacity $(\mathrm{FVC} \%)$ predicted from the PFT values and percent forced expiratory volume in 1 sec $(\mathrm{FEV} / \%)$ were recorded. An IMV duration of $\leq 12 \mathrm{~h}$ was considered normal and $>12 \mathrm{~h}$ was considered prolonged. A length of ICU stay for $\leq 24 \mathrm{~h}$ was considered normal and $>24 \mathrm{~h}$ was considered prolonged. A length of hospital stay for $\leq 7$ days was considered normal and $>7$ was considered prolonged.

Results: As the predicted FVC (\%) value decreased in the preoperative PFTs, the length of IMV, length of ICU and hospital stay increased significantly $\left(\mathrm{p}=0.040, \mathrm{p}=0.036, \mathrm{p}=0.009\right.$, respectively). In terms of the predicted $\mathrm{FEV}_{1}(\%)$ value, as the predicted $\mathrm{FEV} \mathrm{V}_{1}(\%)$ value decreased, the duration of IMV, length of ICU and hospital stay prolonged ( $p=0.023, p=0.044, p=0.024$, respectively).

Conclusion: It is possible to have an idea about postoperative duration of ventilation, ICU and hospital stay based on PFT parameters. Also, the result would be more realistic when adapted to existing scoring systems to assess postoperative complications. Therefore, we believe that scoring systems for evaluating complications after cardiac surgery should include not only chronic lung disease, but also PFT parameters that give a more detailed information.
\end{abstract}

Keywords: Coronary artery bypass grafting, intensive care unit, pulmonary function test.

Coronary artery bypass grafting (CABG), which was first applied in the 1960s, is still a valuable and effective treatment method in the treatment of coronary artery diseases. ${ }^{[1]}$ However, postoperative pulmonary complications such as atelectasis, respiratory failure, and respiratory tract infections that may develop after open heart surgery are the facts we encounter in our daily practice. ${ }^{[2]}$

Factors such as median sternotomy, hypothermia applied to protect the myocardium, pleurotomy and internal mammary artery dissection can have a negative effect on lung functions in the postoperative period. $^{[2,3]}$ Besides, CABG disrupts alveolar stability by creating changes in complement system activation, neutrophil increase in the pulmonary vascular bed, formation of free oxygen radicals and alveolar surfactant production. ${ }^{[4]}$ It is inevitable that atelectasis would develop as a result of changes in the amount of alveolar surfactant and a decrease in alveolar stability. Physiological shunts occur in patients during this period and the alveolo-arterial oxygen gradient increases. ${ }^{[5]}$ Pulmonary complications may occur as a result of all them, leading to a serious cost increase by extending the need for intensive care unit (ICU) and the length of hospital stay. ${ }^{[6]}$

Corresponding author: Yasin Özden, MD. SBÜ Dr. Siyami Ersek Göğüs Kalp ve Damar Cerrahisi Eğitim ve Araştırma Hastanesi, Kalp ve Damar Cerrahisi Kliniği, 34668 Üsküdar, İstanbul, Turkey.

Tel: +90 216 - 5424444 e-mail: dr.yasinozden@gmail.com

\section{Citation:}

Özden Y, Özden Ş, Özçelik S, Köse Y, Şensöz Y, Kayacıoğlu İ. Why should we perform pulmonary function test before coronary artery bypass grafting?. Cardiovasc Surg Int 2021;8(3):145-153. 
In scoring systems that are widely used to assess preoperative cardiac surgery risk (Japan Cardiac Operative Risk Assessment System [JapanSCORE], the Society of Thoracic Surgeons [STS] risk model, and the European Cardiac Risk Assessment System [EuroSCORE II], it is roughly questioned whether there is chronic lung disease. Pulmonary function test (PFT) parameters, which is a very easily applicable and accessible method, are not included in any of these scoring systems ${ }^{[7]}$ However, the need for postoperative ICU and pulmonary complications that may arise can be predicted by the results of PFT in the preoperative period. ${ }^{[8]}$

In the present study, we aimed to examine the relationship between preoperative $\mathrm{PFT}$ parameters and postoperative duration of ventilation, ICU and hospitalization stay.

\section{PATIENTS AND METHODS}

This single-center, retrospective study was conducted at University of Health Sciences, Dr. Siyami Ersek Thoracic and Cardiovascular Surgery Training and Research Hospital, Department of Cardiovascular Surgery between October 2017 and July 2018. A total of 100 patients ( 84 males, 16 females; mean age: $61.1 \pm 10.0$ years; range, 41 to 85 years) who underwent elective CABG surgery for the first time and who did not have any additional cardiac problems, except for coronary artery disease, had an ejection fraction (EF) of $\geq 30 \%$ and underwent preoperative PFTs were included in the study. The PFT was applied to all patients by the traditional method who were scheduled for elective CABG in our hospital. There was no difference between the patients in terms of anesthesia technique or sedative medication. Predicted forced vital capacity percentage (FVC\%) and forced expiratory volume in $1 \mathrm{sec}$ percentage $\left(\mathrm{FEV}_{1} \%\right)$ were recorded. Patients records were obtained from the hospital database. A written informed consent was obtained from each patient. The study protocol was approved by the Istanbul Yedikule Chest Diseases and Thoracic Surgery Training and Research Hospital Clinical Research Ethics Committee (No: 2021-121). The study was conducted in accordance with the principles of the Declaration of Helsinki.

Patients who were taken to ICU with intra-aortic balloon pump (IABP), extracorporeal membrane oxygenation (ECMO) support devices after the operation, patients who had prolonged ICU stay due to reasons other than respiratory functions during ICU follow-up, patients who were re-transferred to the ICU during hospitalization for non-respiratory reasons and patients with prolonged hospitalization due to reasons other than respiratory functions were excluded from the study. The following parameters were considered in the assessment of data:

- An invasive mechanical ventilation (IMV) duration of $\leq 12 \mathrm{~h}$ was considered normal and $>12 \mathrm{~h}$ was considered prolonged.

- A length of ICU stay of $\leq 24 \mathrm{~h}$ was considered normal, $>24 \mathrm{~h}$ is prolonged.

- For the total hospitalization (ICU + ward), a length of stay for $\leq 7$ days was considered normal and $>7$ days was considered prolonged.

\section{Operation technique}

All patients were operated electively. By performing a median sternotomy, arterial cannulation from the ascending aorta and venous cannulation from the right atrium with a two-stage venous cannula was connected to a cardiopulmonary bypass (CPB) device. Moderate hypothermia $\left(28^{\circ} \mathrm{C}\right)$ was achieved, cardiac arrest was achieved with 10 to $15 \mathrm{~mL} / \mathrm{kg}$ cold blood cardioplegia or $5 \mathrm{~mL} / \mathrm{kg}$ cold crystalloid cardioplegia (St. Thomas II) after insertion of the aortic cross-clamp. After the surgical procedure, reperfusion was achieved with $5 \mathrm{~mL} / \mathrm{kg}$ warm blood cardioplegia before the cross-clamp was removed. A roller head pump and hollow fiber membrane oxygenator were used in the $\mathrm{CPB}$ device. Left internal mammary artery (LIMA) and saphenous vein were used as the graft in all patients.

\section{Statistical analysis}

Statistical analysis was performed using the IBM SPSS version 22.0 software (IBM Corp., Armonk, NY, USA). Continuous variables were expressed in mean \pm standard deviation (SD) or median (interquartile range [IQR]), while categorical variables were expressed in number and frequency. The compliance with the normality assumption was tested using the Kolmogorov-Smirnov test. In examining the difference between categorical variables with two groups, the independent samples t-test was used for variables suitable for the assumption of normality, and the Mann-Whitney $U$ test was used for variables not compatible with the assumption of normality. The chi-square test was used to examine the relationship between two categorical variables. A $p$ value of $<0.05$ was considered statistically significant. 


\section{RESULTS}

Of the patients, 72 had a normal weight (body mass index $[\mathrm{BMI}]<30 \mathrm{~kg} / \mathrm{m}^{2}$ ) and $28 \mathrm{had}$ obesity (BMI $\left.\geq 30 \mathrm{~kg} / \mathrm{m}^{2}\right)$. The mean $\mathrm{EF}$ value was $52.6 \pm 8.5 \%$. The mean operation time of the patients was $283.0 \pm 75.6 \mathrm{~min}$, the mean aortic clamp time was $78.1 \pm 52.2 \mathrm{~min}$, and the mean $\mathrm{CPB}$ time was $118.0 \pm 60.7 \mathrm{~min}$. The mean predicted $\mathrm{FEV}_{1}(\%)$ and FVC (\%) values were $90.1 \pm 19.4 \%$ and $83.1 \pm 19.9 \%$, respectively (Table 1 ).

The mean preoperative laboratory test values and chronic disease status of the patients are shown in
Table 2 and Table 3, respectively. None of the patients received blood products and inotropic support in the preoperative period.

Six patients died during the 12-month follow-up period after the operation, 94 of them were still alive. Among deceased patients, the predicted $\mathrm{FEV}_{1}$ (\%) value was $88.3 \pm 26.5 \%$. Among survivors, this value was $90.3 \pm 19.0 \%$, indicating no statistically difference $(\mathrm{p}=0.816)$. The median predicted $\mathrm{FVC}$ values were 74.80 (IQR: 70.88-93.66) for non-survivors and 84.10 (IQR: 71.00-93.60) for survivors $(\mathrm{p}=0.701)$. Although there was no statistically significant difference, predicted FVC values of survivors were higher.

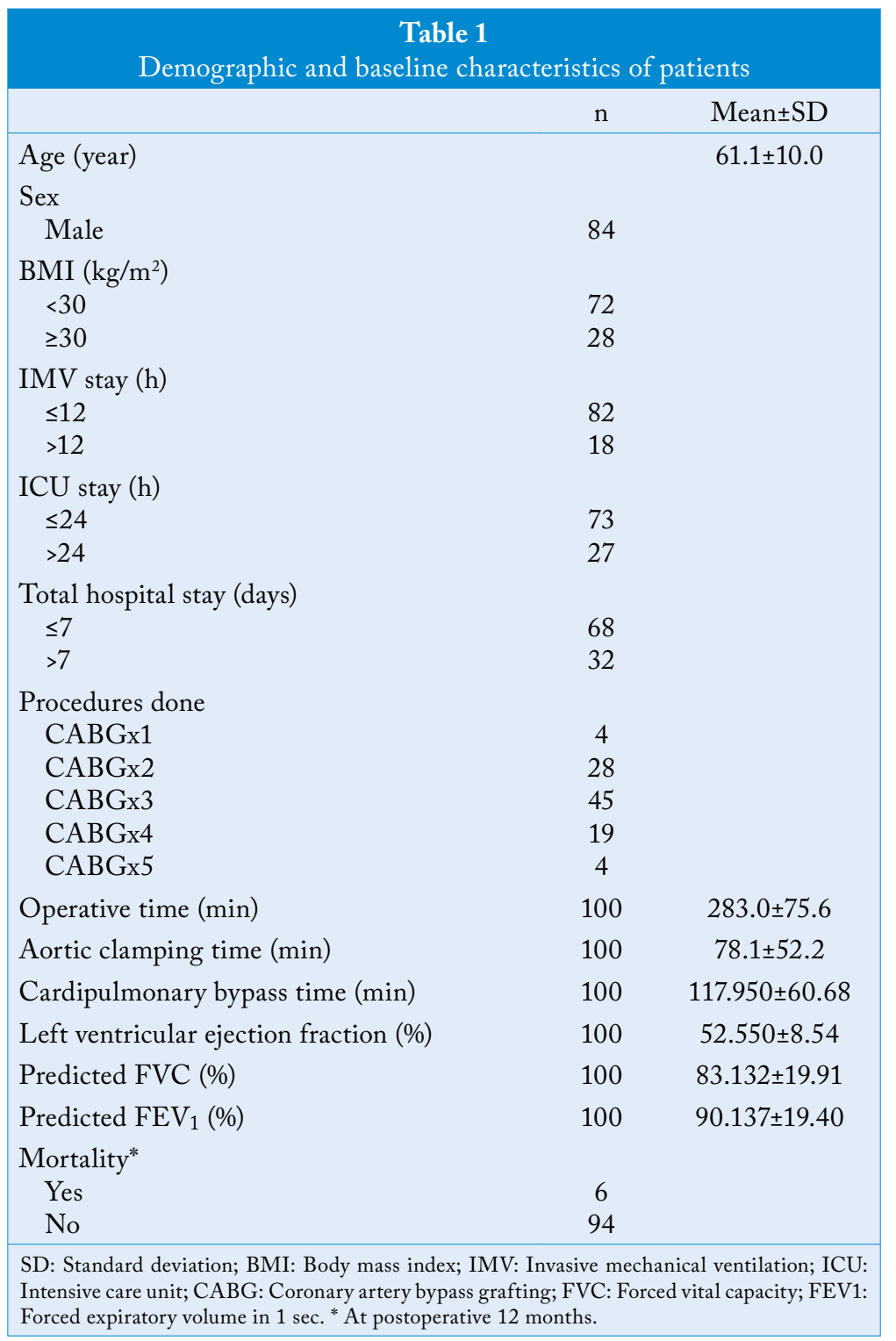




\begin{tabular}{|lc|}
\multicolumn{2}{|c|}{ Table 2} \\
& The mean preoperative laboratory test results \\
\hline WBC $(\mu \mathrm{g} / \mathrm{L})$ & Mean $\pm \mathrm{SD}$ \\
$\mathrm{HGB}(\mathrm{g} / \mathrm{dL})$ & $9.2 \pm 3.5$ \\
HCT $(\%)$ & $13.7 \pm 1.5$ \\
Platelet $(\mu \mathrm{g} / \mathrm{dL})$ & $40.5 \pm 4.5$ \\
Creatine $(\mathrm{mg} / \mathrm{dL})$ & $252.3 \pm 3.1$ \\
Urea $(\mathrm{mg} / \mathrm{dL})$ & $0.9 \pm 0.2$ \\
AST $(\mathrm{u} / \mathrm{L})$ & $18.1 \pm 6.8$ \\
ALT $(\mathrm{u} / \mathrm{L})$ & $24.2 \pm 17.3$ \\
\hline SD: Standard deviation; WBC: White blood cell; HBG: Hemoglobin; HCT: \\
Hematocrit; AST: Aspartate aminotransferase; ALT: Alanine aminotrans- \\
ferase.
\end{tabular}

Duration of ventilation: The relationship between PFT parameters and duration of IMV was evaluated. Accordingly, the median predicted FVC (\%) value of the patients with prolonged IMV duration was 64.00 (IQR: 58.20-90.90), while the median predicted FVC (\%) value of the patients with normal IMV duration was 85.00 (IQR: 74.30-93.95) ( $\mathrm{p}=0.040)$ (Figure 1a). The mean predicted $\mathrm{FEV}_{1}$ (\%) value of the patients with prolonged IMV duration was $82.1 \pm 22.5$, while the mean predicted $\mathrm{FEV}_{1}$ (\%) value of the patients with normal IMV duration was $92.5 \pm 17.8 \quad(p=0.023)$ (Figure 1b).

- The median predicted FVC (\%) value of patients with prolonged IMV duration is 64.00 (IQR: 58.20-90.90), the median predicted FVC (\%) value of patients with normal

(a)

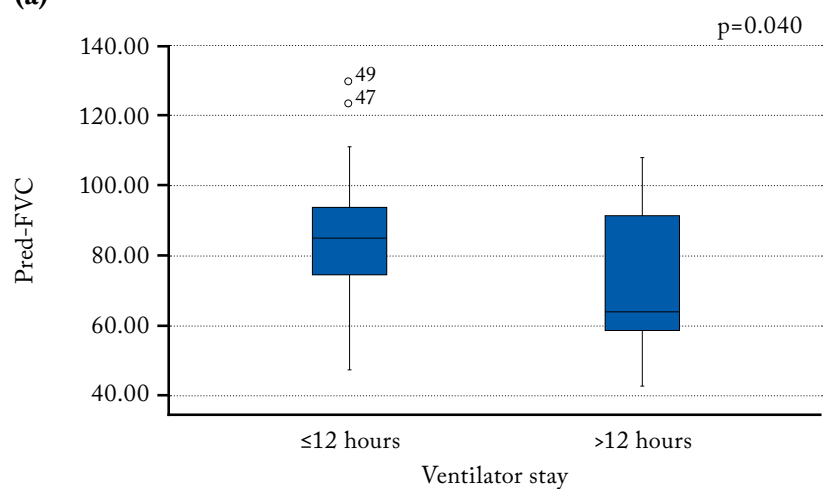

\begin{tabular}{|lc|}
\hline \multicolumn{2}{|c|}{ Table 3 } \\
Preoperative chronic disease status of patients
\end{tabular}

IMV duration is 85.00 (IQR: 74.30-93.95) $(\mathrm{p}=0.040)$ (Figure 1a).

- The mean predicted $\mathrm{FEV}_{1}(\%)$ value of patients with prolonged IMV duration is $82.1 \pm 22.5$, the mean predicted $\mathrm{FEV}_{1}(\%)$ value of patients with normal IMV duration is $92.5 \pm 17.8 \quad(\mathrm{p}=0.023)$ (Figure $1 b)$.

The patients with low predicted $\mathrm{FEV}_{1} \%$ and predicted FVC\% values had have statistically significantly longer IMV.

- When the predicted $\mathrm{FEV}_{1}$ (\%) was divided into two groups as $\geq 80$ and $<80 \%$, the duration of IMV was found as follows: in patients with predicted $\mathrm{FEV}_{1}(\%) \geq 80 \%$, the IMV duration was normal in 57 patients, while

(b)

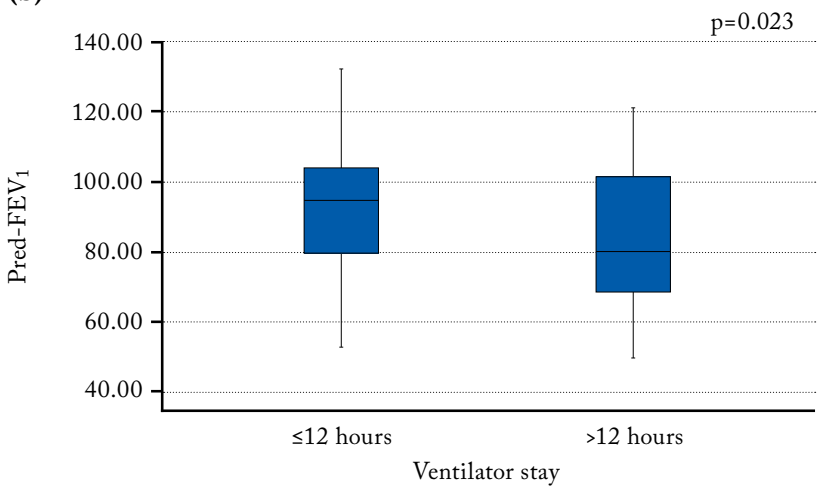

Figure 1. (a) Relationship between IMV and predicted FVC (\%). (b) Relationship between IMV and predicted FEV 1 (\%). IMV: Invasive mechanical ventilation; FVC: Forced vital capacity; FEV : Forced expiratory volume in 1 sec. 
it was prolonged in 11 patients. In patients with predicted $\mathrm{FEV}_{1}(\%)<80 \%$, the IMV duration was normal in 20 patients, while it was prolonged in 12 patients $(\mathrm{p}=0.035)$ (Figure $2 \mathrm{a})$. In patients with predicted $\mathrm{FEV}_{1}(\%) \geq 80 \%$, the IMV duration was normal in 57 patients, while it was prolonged in 11 patients.

- In patients with predicted $\mathrm{FEV}_{1}(\%)<80 \%$, the IMV duration was normal in 20 patients, while it was prolonged in 12 patients $(p=0.035)$ (Figure 2a).

- ICU stay: The relationship between PFT parameters and duration of ICU was examined. Accordingly, the median predicted FVC (\%) value of the patients with prolonged ICU duration was 72.65 (IQR: 58.42-93.30), while the median predicted FVC (\%) value of the patients with normal IMV duration was 81.10 (IQR: 74.90-94.13) ( $p=0.036)$ (Figure 3a). The mean predicted $\mathrm{FEV}_{1}(\%)$ value of the patients with prolonged ICU duration was $82.3 \pm 22.0$, while the mean predicted $\mathrm{FEV}_{1}$ (\%) value of the patients with normal ICU duration was $93.2 \pm 17.5(\mathrm{p}=0.024)$ (Figure $3 \mathrm{~b}$ ). The median predicted FVC (\%) value of patients with prolonged ICU duration is 72.65 (IQR: 58.42-93.30), the median predicted FVC (\%) value of patients with normal IMV duration is 81.10 (IQR: 74.90-94.13) $(\mathrm{p}=0.036)$ (Figure 3a).

- The mean predicted $\mathrm{FEV}_{1}$ (\%) value of patients with prolonged ICU duration is $82.3 \pm 22.0$, the mean predicted $\mathrm{FEV}_{1}$ (\%) value of patients with normal ICU duration is 93.2 $\pm 17.5(p=0.024)$ (Figure 3b).

The patients with low predicted $\mathrm{FEV}_{1} \%$ and predicted $\mathrm{FVC} \%$ values had statistically significantly longer ICU stay.

- When the predicted $\mathrm{FEV}_{1}$ (\%) was divided into two groups as $\geq 80$ and $<80 \%$, the duration of ICU stay was found as follows: in patients with predicted $\mathrm{FEV}_{1}(\%) \geq 80 \%$, the IMV duration was normal in 54 patients, while it was prolonged in 14 patients. In patients with predicted $\mathrm{FEV}_{1}(\%)<80 \%$, the IMV duration was normal in 18 patients, while it was prolonged in 14 patients $(p=0.030)$ (Figure 2b). In patients with predicted $\mathrm{FEV}_{1}$ (\%) $\geq 80 \%$, the IMV duration was normal (a)

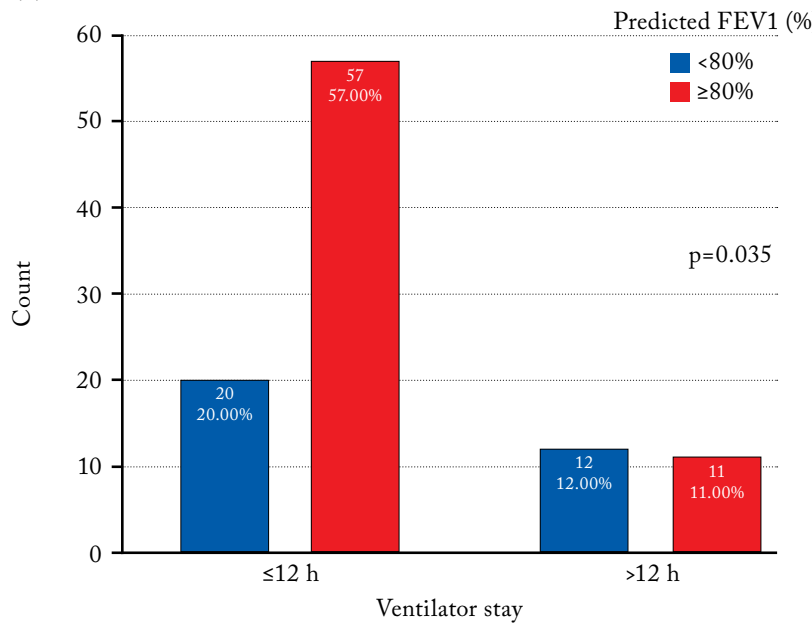

(b)

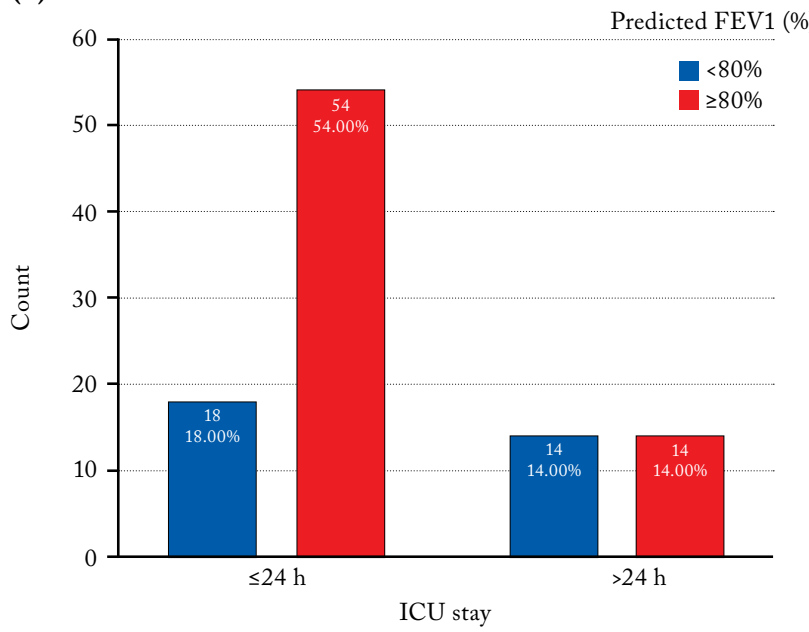

(c)

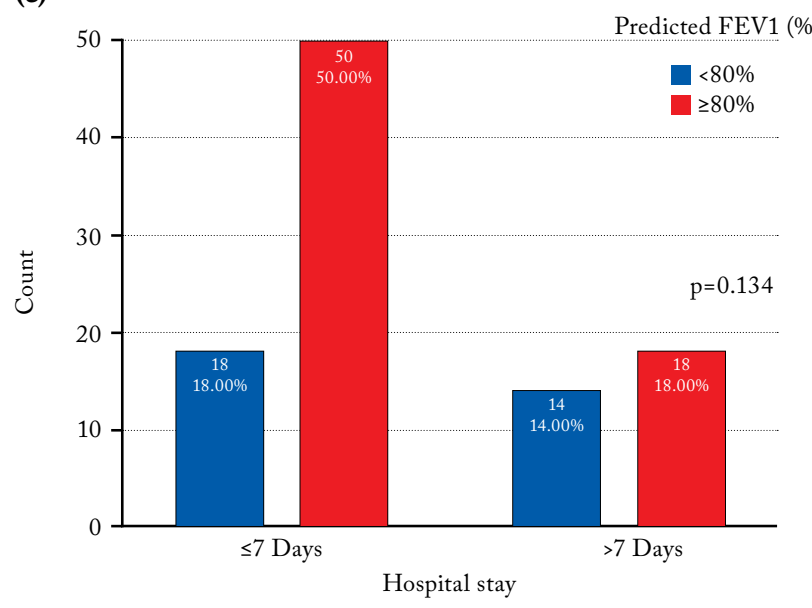

Figure 2. Relationship between ventilator, ICU and hospital stay in patients with predicted FEV1 (\%) $\geq 80$ and $<80 \%$.

FEV1: Forced expiratory volume in $1 \mathrm{sec}$. 

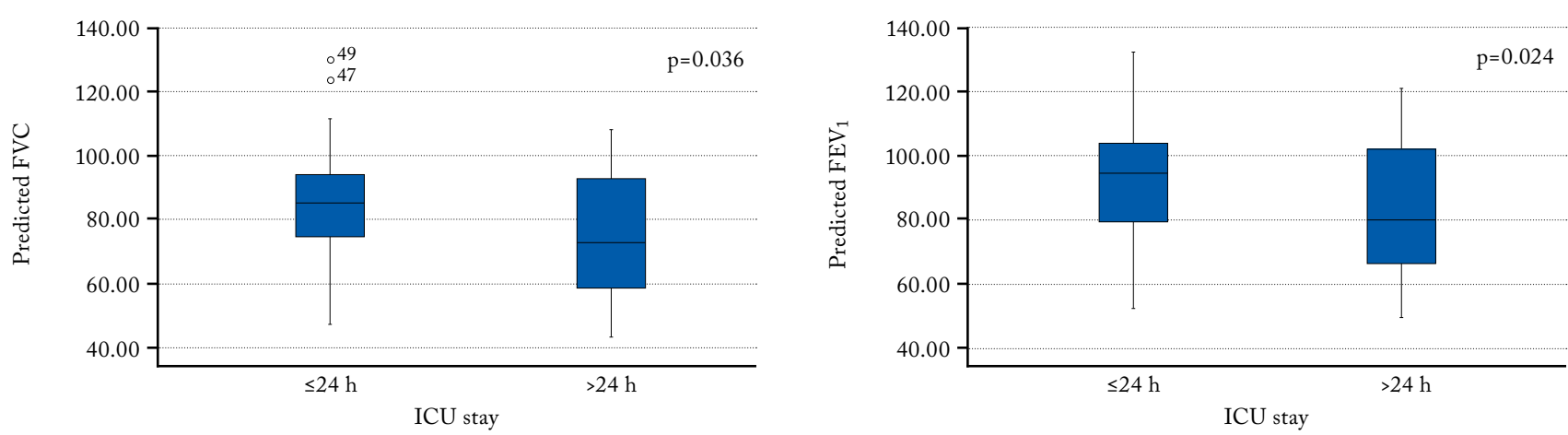

Figure 3. (a) Relationship between ICU stay and predicted FVC (\%). (b) Relationship between ICU stay and predicted FEV 1 (\%). ICU: Intensive care unit; FVC: Forced vital capacity; $\mathrm{FEV}_{1}$ : Forced expiratory volume in $1 \mathrm{sec}$.

in 54 patients, while it was prolonged in 14 patients.

- In patients with predicted $\mathrm{FEV}_{1}(\%)<80 \%$, the IMV duration was normal in 18 patients, while it was prolonged in 14 patients $(\mathrm{p}=0.030)$ (Figure 2b).

\section{Hospital stay}

The relationship between PFT parameters and duration of hospitalization was examined. Accordingly, the median predicted FVC (\%) value of the patients with prolonged duration of hospitalization was 81.65 (IQR: 59.33-88.85), while the median predicted FVC (\%) value of the patients with normal duration of hospitalization was 86.50 (IQR: 73.36-96.45) $(\mathrm{p}=0.009)$ (Figure $4 \mathrm{a})$. The median predicted $\mathrm{FEV}_{1}$ (\%) value of the patients with prolonged duration of

(a)

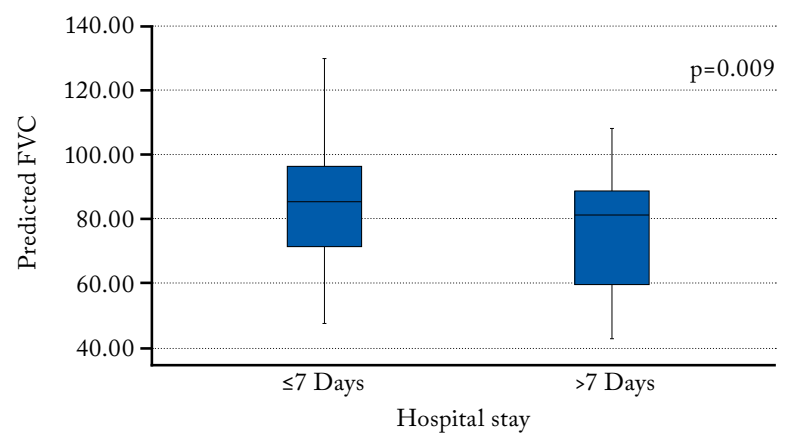

hospitalization was 85.95 (IQR: 70.15-85.95), while the median predicted $\mathrm{FEV}_{1}(\%)$ value of the patients with normal duration of hospitalization was 92.15 (IQR: 79.60-92.15) ( $\mathrm{p}=0.044)$ (Figure 4b).

- The median predicted FVC (\%) value of patients with prolonged duration of hospitalization is 81.65 (IQR: 59.33-88.85), the median predicted FVC (\%) value of patients with normal duration of hospitalization is 86.50 (IQR: 73.36-96.45) ( $\mathrm{p}=0.009)$ (Figure 4a).

- The median predicted $\mathrm{FEV}_{1}$ (\%) value of patients with prolonged duration of hospitalization is 85.95 (IQR: 70.15-85.95), the median predicted $\mathrm{FEV}_{1}$ (\%) value of patients with normal duration of hospitalization is 92.15 (IQR: 79.60-92.15) $(\mathrm{p}=0.044)$ (Figure $4 \mathrm{~b})$.

(b)

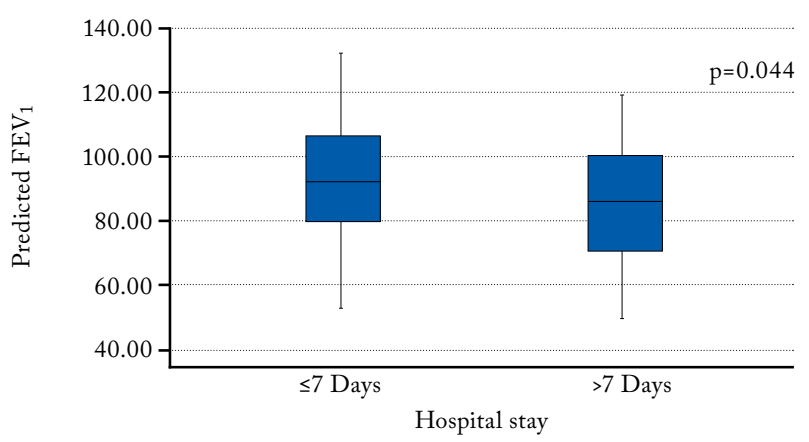

Figure 4. (a) Relationship between hospital stay and predicted FVC (\%). (b) Relationship between hospital stay and predicted $\mathrm{FEV}_{1}(\%)$.

FVC: Forced vital capacity; FEV F $_{1}$ Forced expiratory volume in $1 \mathrm{sec}$. 
The patients with low predicted $\mathrm{FEV}_{1} \%$ and predicted $\mathrm{FVC} \%$ values had statistically significantly longer hospitalization stay.

- When the predicted $\mathrm{FEV}_{1}(\%)$ was divided into two groups as $\geq 80$ and $<80 \%$, the duration of IMV was found as follows: in patients with predicted $\mathrm{FEV}_{1}(\%) \geq 80 \%$, the hospitalization stay duration was normal in 50 patients, while it was prolonged in 18 patients. In patients with predicted $\mathrm{FEV}_{1}(\%)<80 \%$, the hospitalization stay duration was normal in 18 patients, while it was prolonged in 14 patients $(p=0.134)$ (Figure 2c). In patients with predicted $\mathrm{FEV}_{1}$ (\%) $\geq 80 \%$, the hospitalization stay duration was normal in 50 patients, while it was prolonged in 18 patients.

- In patients with predicted $\mathrm{FEV}_{1}(\%)<80 \%$, the hospitalization stay duration was normal in 18 patients, while it was prolonged in 14 patients $(\mathrm{p}=0.134)$ (Figure $2 \mathrm{c}$ ).

\section{DISCUSSION}

In the present study, the relationship between predicted $\mathrm{FEV}_{1}(\%)$ and predicted $\mathrm{FVC}(\%)$ values and duration of ventilation, length of ICU and hospital stay was examined. According to the results, as the preoperative predicted $\mathrm{FEV}_{1}(\%)$ and predicted $\mathrm{FVC}$ (\%) values decreased, the duration of ventilation, length of ICU and hospital stay statistically significantly increased.

In a study, Alam et al ${ }^{[8]}$ showed that predicted $\mathrm{FEV}_{1}$ (\%) and FVC (\%) were good predictors of postoperative pulmonary complications (e.g., respiratory failure, atelectasis, and pulmonary infections). In the aforementioned study, as the rate of predicted $\mathrm{FEV}_{1}$ (\%) decreased, the rate of respiratory failure and atelectasis increased ( $\mathrm{p}=0.003$ vs. $\mathrm{p}<0.001$, respectively).

An initial decrease of 40 to $50 \%$ in $\mathrm{FEV}_{1}$ (\%) and FVC (\%) values on the first and third days after CABG is expected. ${ }^{[9,10]}$ There is a study showing that there is a significant decrease in $\mathrm{FEV}_{1}$ (\%) and FVC (\%) values in three-year follow-ups of PFT parameters in patients with $\mathrm{CABG}$ compared to the preoperative period. ${ }^{[11]}$ Therefore, in patients with low $\mathrm{FEV}_{1}$ (\%) in the preoperative period, a greater reduction in $\mathrm{FEV}_{1}(\%)$ and hypoxia in the postoperative period would be inevitable. In our study, when we divided and examined patients into two groups as predicted $\mathrm{FEV}_{1}(\%) \geq 80 \%$ and predicted $\mathrm{FEV}_{1}(\%)<80 \%$, the group with predicted $\mathrm{FEV}_{1} \geq 80 \%$ had a shorter ICU stay and ventilation duration than those with predicted $\mathrm{FEV}_{1}<80 \%$ ( $\mathrm{p}=0.030$ and $\mathrm{p}=0.035$, respectively). However, there was no statistically difference between the two groups in terms of length of hospital stay $(\mathrm{p}=0.134)$.

In a study by Kshirsagar et al., ${ }^{[12]} 370$ patients who underwent $\mathrm{CABG}$ between the ages of 35 and 65 years, the duration of hospital stay increased significantly as $\mathrm{FEV}_{1}$ (\%) decreased. In another study by Saleh et al. ${ }^{[13]}$ including a large number of patients $(n=11,217)$, the patients were divided into three groups according to the severity of chronic obstructive pulmonary disease (COPD) $\left(\mathrm{FEV}_{1} / \mathrm{FVC}<70 \%\right.$ and predicted $\mathrm{FEV}_{1} \geq 80 \%$ : mild COPD; $\mathrm{FEV}_{1} / \mathrm{FVC}<70 \%$ and $\leq 50 \%$ predicted $\mathrm{FEV}_{1}<80 \%$ : moderate COPD; and $\mathrm{FEV}_{1} / \mathrm{FVC}<70 \%$ and $\leq 30 \%$ predicted $\mathrm{FEV}_{1}<50 \%$ : severe COPD). Accordingly, as the severity of COPD increased, many pulmonary disease complications such as inotropic support, acute renal failure, and early mortality increased significantly. Similar to our study, it was shown that there was a negative correlation between $\mathrm{FEV}_{1}(\%)$ and hospital stay. In another study by the aforementioned authors, a reduced $\mathrm{FEV}_{1}(\%)$ (odds ratio [OR]: 0.99; 95\% confidence interval [CI]: $0.98-0.99$ ) occurred in $1.96 \%$ of CABG patients which was a preoperative predictor of prolonged mechanical ventilation. ${ }^{[14]}$

Prolonged duration of mechanical ventilation after CABG also extends the length of ICU and hospital stay. It is known to cause a decrease in early and mid-term survival. ${ }^{[7]}$ Hulzebos et al. ${ }^{[15]}$ suggested that preoperative pulmonary muscle physiotherapy could reduce postoperative hospital stay and the incidence of pulmonary complications. In a meta-analysis, the length of ICU stay and hospital stay could be reduced, particularly in elderly patients, with interventions in the preoperative period (e.g., inspiratory muscle physiotherapy, pulmonary exercise physiotherapy).

In the postoperative 12-month follow-up, although there was no statistically difference between the predicted $\mathrm{FEV}_{1}$ (\%) and FVC (\%) values of the survivors and non-survivors, the median predicted FVC values of the survivors were higher than those with non-survivors. Patients with moderate and severe airway obstruction $\left(\mathrm{FEV}_{1} / \mathrm{FVC}<70 \%\right.$ and $\mathrm{FEV}_{1}(\%)$ $<80 \%)$ had a 3.2 times higher mortality than patients 
without airway obstruction in the study of Adabag et $\mathrm{al}^{[16]}$ (95\% CI: 1.6-6.2, p=001).

In the literature, it has been shown that EuroSCORE is the best scoring system that can predict 30-day and 12-month mortality after cardiac surgery. ${ }^{[17]}$ On the other hand, studies have been carried out on many different parameters that are thought to be missing in this scoring system. ${ }^{[18]}$ McAllister et al. ${ }^{[19]}$ created two scoring groups to determine mortality after cardiac surgery: (i) EuroSCORE and (ii) $\mathrm{FEV}_{1}$ (\%) values added to the EuroSCORE. As a result, the EuroSCORE scoring system with $\mathrm{FEV}_{1}$ (\%) values was more successful in predicting mortality.

The main limitations of this study include its single-center, retrospective design with a relatively small sample size. In addition, since the study design was retrospective, smoking history and biomass exposure affecting PFT parameters in the preoperative period could not be taken into account.

In conclusion, spirometry is an easily accessible, simple-to-use method that does not require serious costs and is used to evaluate the lung physiological reserve. It is possible to have an idea about postoperative durations of ventilation, ICU and hospital stay based on the PFT parameters. Also, the result would be more realistic when adapted to existing scoring systems to assess postoperative complications. Therefore, we believe that scoring systems for evaluating complications after cardiac surgery should include not only chronic lung disease, but also PFT parameters that give a more detailed information.

\section{Declaration of conflicting interests}

The authors declared no conflicts of interest with respect to the authorship and/or publication of this article.

\section{Funding}

The authors received no financial support for the research and/or authorship of this article.

\section{REFERENCES}

1. Head SJ, Kieser TM, Falk V, Huysmans HA, Kappetein AP. Coronary artery bypass grafting: Part 1--the evolution over the first 50 years. Eur Heart J 2013;34:2862-72.

2. Roosens C, Heerman J, De Somer F, Caes F, Van Belleghem Y, Poelaert JI. Effects of off-pump coronary surgery on the mechanics of the respiratory system, lung, and chest wall: Comparison with extracorporeal circulation. Crit Care Med 2002;30:2430-7.
3. Lichtenberg A, Hagl C, Harringer W, Klima U, Haverich A. Effects of minimal invasive coronary artery bypass on pulmonary function and postoperative pain. Ann Thorac Surg 2000;70:461-5.

4. Fuster RG, Argudo JA, Albarova OG, Sos FH, López SC, Codoñer MB, et al. Prognostic value of chronic obstructive pulmonary disease in coronary artery bypass grafting. Eur J Cardiothorac Surg 2006;29:202-9.

5. Hanözü M. Açık kalp cerrahisi sonrası gelişen torasik komplikasyonlar [Doctoral Thesis]. Department of Thoracic Surgery, Dr Siyami Ersek Thoracic and Cardiovascular Surgery Training and Research Hospital, Istanbul, Turkey. 2006.

6. Mortasawi A, Arnrich B, Rosendahl U, Frerichs I, Albert A, Walter $\mathrm{J}$, et al. Is age an independent determinant of mortality in cardiac surgery as suggested by the EuroSCORE? BMC Surg 2002;2:8.

7. Fujii M, Nishina D, Bessho R. Preoperative assessment of pulmonary function tests and outcomes after cardiac surgery. Heart Surg Forum 2020;23:E245-E249.

8. Alam M, Shehzad MI, Hussain S, Paras I, Kanwal M, Mushtaq A. Spirometry assessment and correlation with postoperative pulmonary complications in cardiac surgery patients. Cureus 2020;12:e11105.

9. Nicholson DJ, Kowalski SE, Hamilton GA, Meyers MP, Serrette C, Duke PC. Postoperative pulmonary function in coronary artery bypass graft surgery patients undergoing early tracheal extubation: A comparison between shortterm mechanical ventilation and early extubation. J Cardiothorac Vasc Anesth 2002;16:27-31.

10. Matte P, Jacquet L, Van Dyck M, Goenen M. Effects of conventional physiotherapy, continuous positive airway pressure and non-invasive ventilatory support with bilevel positive airway pressure after coronary artery bypass grafting. Acta Anaesthesiol Scand 2000;44:75-81.

11. İnönü $\mathrm{H}$, Naseri $\mathrm{E}$, Çelikel $\mathrm{S}$, Pazarlı AC, Etikan İ. Kalp cerrahisinin erken ve geç pulmoner fonksiyonlar üzerine etkisi: Üç yıllık takip sonuçları. Turk Gogus Kalp Dama 2011;19:144-50.

12. Kshirsagar D, Beke N, Khadke V, Phalgune D. Pulmonary function tests in patients undergoing coronary artery bypass graft surgery and its correlation with outcome. J Assoc Physicians India 2020;68:39-42.

13. Saleh HZ, Mohan K, Shaw M, Al-Rawi O, Elsayed H, Walshaw $\mathrm{M}$, et al. Impact of chronic obstructive pulmonary disease severity on surgical outcomes in patients undergoing non-emergent coronary artery bypass grafting. Eur J Cardiothorac Surg 2012;42:108-13.

14. Saleh HZ, Shaw M, Al-Rawi O, Yates J, Pullan DM, Chalmers JA, et al. Outcomes and predictors of prolonged ventilation in patients undergoing elective coronary surgery. Interact Cardiovasc Thorac Surg 2012;15:51-6.

15. Hulzebos EH, Helders PJ, Favié NJ, De Bie RA, Brutel de la Riviere A, Van Meeteren NL. Preoperative intensive inspiratory muscle training to prevent postoperative pulmonary complications in high-risk patients undergoing CABG surgery: A randomized clinical trial. JAMA 2006;296:1851-7. 
16. Adabag AS, Wassif HS, Rice K, Mithani S, Johnson D, Bonawitz-Conlin J, et al. Preoperative pulmonary function and mortality after cardiac surgery. Am Heart J 2010;159:691-7.

17. Nilsson J, Algotsson L, Höglund P, Lührs C, Brandt J. Comparison of 19 pre-operative risk stratification models in open-heart surgery. Eur Heart J 2006;27:867-74.

18. Tarçın Ö, Orhan G, Nehir Tandogar U, Mihmanlı M,
Baştopçu M, Yekeler İ. Does thyroid dysfunction affect early mortality and morbidity after coronary artery bypass graft surgery? Cardiovasc Surg Int 2018;5:1-8.

19. McAllister DA, Wild SH, MacLay JD, Robson A, Newby DE, MacNee W, et al. Forced expiratory volume in one second predicts length of stay and in-hospital mortality in patients undergoing cardiac surgery: A retrospective cohort study. PLoS One 2013;8:e64565. 